\title{
Interactive comment on "Basin-scale multi-objective simulation-optimization modeling for conjunctive use of surface water and groundwater in northwest China" by Jian Song et al.
}

\section{Qiankun Luo}

qialuo@ethz.ch

Received and published: 14 September 2019

This manuscript focus on the topic of conjunctive using of surface water and groundwater based on the multi-objective simulation and optimization method. In the manuscript, a novel multi-objective optimization model with four objective functions is developed to balance the water demand for agriculture, socioeconomic development and environmental demands. In order to find the Pareto optimal solutions for the special model, a new multi-objective evolutionary algorithm, named ÉŻ-MOMA, is presented. The optimization results of Yanqi Basin (YB) in northwest China certified the applicability of

Printer-friendly version

Discussion paper 
the new model and optimization algorithm. Generally, the manuscript does make an important contribution on water resources management research. However, there are some general and specific comments referencing lines in the manuscript which will be helpful for the improvement of the manuscript.

General comments: 1 . The introduction usually includes the research background, the research problems, a review of the advantages and disadvantages of the previous and latest research results, and the new solving method of the present research. Thus, the description of the detailed condition of the study area should be move into section 3.1. 2. The advantage of the newly developed optimization algorithm should be given in detail. For example, why the ÉŻ-MOMA is better than the other MOEA in solving groundwater management problems? What is the main difference between ÉŻ-box and the elite individual preservation strategy? 3 . In the numerical simulation process, the irrigation backflow should be considered. How to deal with the irrigation backflow in the groundwater flow numerical simulation model of the YB? 4. YB is a typical arid inland basin in China. The optimization results of YB are seemed reliably, can this optimization model be used directly in other basin or field?

Specific comments: 1. Line 168: I suggest to changing the "decision-maker" to "water manager" in the manuscript. The author sometimes uses "decision-maker" and sometimes uses "water manager", which will confuse the readers. 2. Line 199-201: Did all of the referred recombination operators (SBX, DE, SPX, PCX, LX, UM) used in the new optimization method? Or only one of them was adopted? The author should clear it. 3. Line 291: There is a mistake in Equation 4, the "2" was lost. 4. Line 417: where the increment of fTPR and fTDR from, the explanation should be given. 5. Line 539-541: Why the lake level is changed to a smaller value? And why the maximum groundwater drawdown is reset to $10 \mathrm{~m}$ ? 6 . Line 557: "a certain value" should be given explicitly for the case study. 7. Line 578: Change "Yanqi Basin" to "YB".

Interactive comment on Hydrol. Earth Syst. Sci. Discuss., https://doi.org/10.5194/hess-2019-

Printer-friendly version

Discussion paper 
278, 2019.

HESSD

Interactive

comment

Printer-friendly version

Discussion paper

(c) (i) 